\title{
Гідродинаміка та теплообмін під час конденсації пари робочих речо- вин у середині горизонтальних труб у разі стратифікованого режиму течії фаз. Огляд праць
}

\author{
В. В. Горін ${ }^{1}$, В. В. Середа ${ }^{2}$ \\ ${ }^{1}$ Одеська державна академія технічного регулювання та якості, вул. Ковальська, 15, м. Одеса, 65020, Україна \\ ${ }^{2}$ Національний університет водного господарства та природокористування, вул. Соборна, 11, м. Рівне, 33028, Україна \\ E-mail: ${ }^{1}$ gorin53@ukr.net, ${ }^{2}$ volodya.81.vs@gmail.com
}

\begin{abstract}
У праці проаналізовано теоретичні та експериментальні моделі та методи розрахунку гідродинаміки і теплообміну під час конденсації робочих речовин у середині горизонтальних труб у разі стратифікованого режиму течії фаз із відкритих літературних джерел. Систематизовано наявні теоретичні та експериментальні рішення щзодо розрахунку кута затоплення струмком конденсату частини перерізу труби у разі стратифікованого та стратифіковано-хвильового режимів течї фаз. Водночас наведено корелячії різних авторів стосовно розрахунку локальних та середніх за периметром труби коефіцієнтів тепловіддачі. Також наведено рішення згідно із сучасними механістичними моделями, за якими основні фізичні закони використовують для моделювання характеристик потоку, зокрема таких, як прогнозування режимів течії. Також у праці обтрунтовано необхідність нових досліджень щзодо пошуку оптимальних рішень для розрахунку теплообміну під час конденсації в середині горизонтальних труб у разі стратифікованого режиму течії.
\end{abstract}

Ключові слова: конденсачія, теплообмін, математична модель, кут затоплення труби, стратифікований режим,коефіцієнт тепловіддачі.

C) The Author(s) 2018. This article is an open access publication

This work is licensed under the Creative Commons Attribution 4.0 International License (CC BY) http://creativecommons.org/licenses/by/4.0/

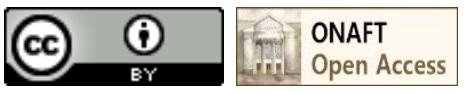

\section{I. ВСТУП}

У разі течії рідини в горизонтальних конденсаторах на значній частині поверхні труб конденсаторів наявний стратифікований (розшарований) режим течії. Знаходження частини перерізу труби, яку займає струмок конденсату, $є$ важливим питанням через те, що рівень струмка суттєво впливає на значення коефіцієнтів тепловіддачі під час конденсації пари в середині труб.

Серед значної кількості наукових робіт, присвячених проблемам гідродинаміки і теплообміну під час конденсації в середині горизонтальних труб у разі стратифікованого режиму течії фаз, немає чіткої визначеності у загальних рекомендаціях щодо використання запропонованих розрахункових залежностей.

У праці наведено огляд результатів наукових досліджень різних науковців стосовно гідродинаміки і теплообміну під час конденсації в середині труби у разі стратифікованого режиму течії фаз. Ця робота $є$ першою частиною серії досліджень гідродинаміки й теплообміну під час конденсації в середині труб у разі стратифікованого режиму течії фаз.

\section{І. ТЕОРЕТИЧНІ МОДЕЛІ ТА МЕТОДИ РОЗРА- ХУНКУ ТЕПЛООБМІНУ ПІД ЧАС СТРАТИФІ- КОВАНОГО РЕЖИМУ ТЕЧІЇ ФАЗ}

У разі протікання двофазної течії в горизонтальній трубі можливий широкий діапазон режимів течії фаз. 3 такого діапазону виокремлюють типові режими, які узагальнено описують усю структуру течії двофазного потоку у горизонтальній трубі. Розподіл цих режимів по довжині труби залежить від фізичних властивостей пари та конденсату, діаметра труби, швидкості пари i теплового потоку. У разі перевищення силою тяжіння сили міжфазного тертя за низькими значеннями паровмісту $x$ (однак $x>0$ ) спостерігається стратифікований (розшарований режим) течії фаз. У цьому разі у верхній частині труби конденсат стікає фактично під кутом близько $90^{\circ}$ до горизонталі, а в нижній частині тече у вигляді струмка за рахунок градієнта статичного тиску. За низьких швидкостей пари на вході у трубу такий характер перебігу фаз може простежуватися по всій довжині горизонтальної труби.

Наявні теоретичні розв'язки задачі конденсації в середині гладких горизонтальних труб виконано для двох режимів двофазного потоку: для розшарованого або стратифікованого режиму, де сили тяжіння суттєво впливають на теплообмін, та для кільцевого режиму, коли впливом сил тяжіння можна нехтувати.

\section{1. Кореляція Нуссельта [1]}

Під час стратифікованого режиму течії фаз у всіх теоретичних працях використовують залежність Нуссельта [1], яку отримано за умови конденсації нерухомої пари на горизонтальній трубі:

$$
\bar{\alpha}=0,728\left(\frac{\rho_{l}\left(\rho_{l}-\rho_{v}\right) g r \lambda_{l}^{3}}{\mu_{l} d \Delta T}\right)^{1 / 4} .
$$

Залежність (1) можна коригувати емпіричними поправками, які враховують наявність струмка конденсату в нижній частині труби. Тепловіддачу в струмку, що залежить від його глибини, розраховують за залежностями конвективного теплообміну. 


\section{2. Залежності Консетова [2; 3]}

1.2.1. Кут затоплення струмка конденсату

Автор роботи [2] теоретичним способом отримав залежності розрахунку кута затоплення і тепловіддачі під час конденсації у горизонтальних труб малого діаметра, які застосовують у конденсаторах.

Половинний кут затоплення на кінці труби $\varphi$, у першому наближенні, можна розраховувати за залежністю для безрозмірної висоти струмка:

$$
1-\cos \varphi=4,2 F r^{\frac{1}{3}}\left(\frac{\sigma}{\rho_{l} g d_{i}^{2}}\right)^{1 / 4} .
$$

Коли конденсацію пари розраховують за середнім значення густини теплового потоку $F r=\overline{q l} /\left(r \rho_{l} \sqrt{g d_{i}^{3}}\right)$.

Для горизонтальних труб кут затоплення збільшується наприкінці труби, проте цим підвищенням можна знехтувати i користуватися значенням половинного кута затоплення на виході ф.

Автор зауважує, що сили поверхневого натягу також впливають на форму струмка по всій довжині труби. Завдяки дії сил поверхневого натягу поверхня струмка плавно сполучається із циліндричною поверхнею плівки (рис. 1). Розрахунки автора доводять, що безрозмірний половинний кут затоплення струмка збільшується на значення

$$
\frac{\varphi_{\sigma}}{\pi} \square \sqrt{\frac{\sigma}{\rho_{l} g d_{i}^{2}}},
$$

при цьому за струмок умовно обирають ту частину плівки, у якої товщина в 4-5 разів більша від товщини плівки, що визначалася тільки силами тяжіння.

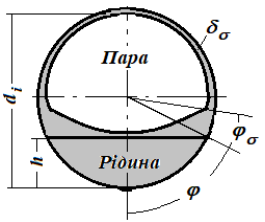

Рисунок 1. Схема течї струмка

Ураховуючи зазначене, залежність має такий виpa3:

$$
\varphi_{0}=\arccos \left[1-4,2 F^{1 / 3}\left(\frac{\sigma}{\rho_{l} g d_{i}^{2}}\right)^{1 / 4}\right]+\pi\left(\frac{\sigma}{\rho_{l} g d_{i}^{2}}\right)^{1 / 2} .
$$

Остаточно кут струмка конденсату (змоченої частини труби) дорівнює $\theta_{w e t}=2 \varphi_{0}$.

У дисертації [3] автор наводить формулу для розрахунку кута затоплення струмком конденсату в трубі з нахилом. За підходом, запропонованим у праці [2], автор із диференціальних рівнянь руху та безперервності для елемента струмка отримав залежність для розрахунку кута затоплення для труб із нахилом:

$$
\varphi_{0}=c \operatorname{Re}^{n} G a^{-m}+\pi\left(\frac{\sigma}{\rho_{l} g d_{i}^{2}}\right)^{0,5},
$$

де $\operatorname{Re}=q l / r \mu_{l} \quad-$ критерій Рейнольдса плівки; $G a=\frac{g d_{i}^{3}}{v_{l}^{2}} \sin \beta-$ критерій Галілея; $\beta$ - кут нахилу поздовжньої осі труби до лінії горизонту.

Стала $c$ та показники ступенів $n$ i $m$ установлюють із дослідів. Так, за ламінарним режимом течії струмка за $R e<3000, c=3,8 ; n=m=1 / 6$; за турбулентним режимом течії $\operatorname{Re}>3000 c=1,55 ; n=0,26 ; m=1 / 7$.

\subsection{2. Визначення коефіціснта тепловіддачі}

Відповідно до праці [2] середній коефіцієнт тепловіддачі $\alpha$ під час конденсації пари в середині горизонтальної труби за умови наявності на її більшій частині розшарованого режиму течії двофазного потоку наближено дорівнює:

$$
\bar{\alpha} \square \frac{\bar{\varphi}}{\pi} \bar{\alpha}_{c m p}+\frac{\pi-\bar{\varphi}}{\pi} \bar{\alpha}_{n l},
$$

де $\alpha_{c m p}$ і $\alpha_{n л}-$ відповідно середні коефіцієнти тепловіддачі струмка конденсату (нижня частина труби) i у верхній частині труби (плівка конденсату); $\phi-$ середній кут затоплення.

Здебільшого середній коефіцієнт тепловіддачі струмка конденсату $\alpha_{c m p}$ значно менший порівняно із середнім коефіцієнтом тепловіддачі у верхній частині труби $\alpha_{\text {пл}}$, отже коефіцієнтом тепловіддачі $\alpha_{c m p}$ можна знехтувати. Тоді формула (5) спрощується до вигляду:

$$
\bar{\alpha} \square \frac{\pi-\bar{\varphi}}{\pi} \bar{\alpha}_{n i} .
$$

Коефіцієнт тепловіддачі $\alpha_{n л}$ розраховують за рівнянням Нуссельта для конденсації пари на зовнішній поверхні труби $\alpha_{N u} 3$ поправкою $B_{\varphi}$ на змінювання границь інтегрування від 0 до $(\pi-\phi)$ :

$$
\bar{\alpha}_{n l}=B_{\varphi}\left(\frac{\lambda^{3} \rho_{l} g r}{v d_{i} q}\right)^{1 / 3} .
$$

Графічне інтегрування рівняння Нуссельта для горизонтальної труби і подальша апроксимація дають для $B_{\varphi}$ таке рівняння

$$
B_{\phi}=(1+9 \cdot \bar{\phi} / \pi)^{0,1} .
$$

\section{3. Модель розрахунку теплообміну Thome et al.}

У працях [5] запропоновано модель розрахунку теплообміну під час конденсації в середині горизонтальної труби за різними режимами течії фаз, яка грунтується на спрощеній структурі режимів течії. Цей метод часто використовують дослідники під час порівняння 3 результатами експериментів.

Загальна кореляція (6) для розрахунку локального коефіцієнта тепловіддачі під час конденсації має наступний вираз

$$
\alpha_{t p}=\frac{\alpha_{f} r \theta+(2 \pi-\theta) r \alpha_{c}}{2 \pi r}
$$

де

$$
\begin{aligned}
& \alpha_{f}=0,655\left(\frac{\rho_{l}\left(\rho_{l}-\rho_{v}\right) g r \lambda_{l}^{3}}{\mu_{l} d q}\right)^{1 / 3} ; \\
& \alpha_{c}=c \operatorname{Re}_{l}^{n} \operatorname{Pr}_{l}^{m} \frac{\lambda_{l}}{\delta} f_{i} .
\end{aligned}
$$

Визначальним розміром у виразі (8) обрано товщину плівки конденсату $\delta$, яку розраховують за залежністю

$$
\delta=d(1-\varepsilon) / 4, \operatorname{Re}_{l}=[4 G(1-x) \delta] /\left[(1-\varepsilon) \mu_{l}\right] .
$$

У праці [4-8] автори використовують кореляцією (6) за $f_{i}=1,0 ; c=0,0039 ; n=0,734 ; m=0,5$. У працях [5-9] тепловіддачу розраховують уже за $c=0,003 ; n=$ 0,$74 ; m=0,5$, а множник $f_{i}$ визначають за залежністю 


$$
f_{i}=1+\left(u_{v} / u_{l}\right)^{0,5}\left[\left(\rho_{l}-\rho_{v}\right) g \delta^{2} / \sigma\right]^{0,25},
$$

де $u_{v}=\frac{G x}{\rho_{v} \varepsilon} ; u_{l}=\frac{G(1-x)}{\rho_{l}(1-\varepsilon)}-$ середні швидкості пари та рідини відповідно.

У формулі (6) для кільцевого, проміжного та дисперсного режимів $\theta=0$. Для стратифіковано-хвильового потоку стратифікований кут $\theta_{\text {strat }}$ утворюється, якщо взяти квадратичну інтерполяцію між його максимальним значенням за $G_{\text {strat }}$ та його мінімальним значенням 0 за хвильового режиму $G_{\text {wavy }}$.

Для оцінювання об'ємного паровмісту $\varepsilon$ автори праць [5] вводять у розрахунок режимів об'ємний паровміст, значення якого розраховують за формулою (10), як середнє логарифмічне між об'ємними паровмістами $\varepsilon_{h}$ та $\varepsilon_{r a}$, що визначаються за формулою для гомогенної течії (11) та формулою (12) із праць [6-10] відповідно:

$$
\begin{aligned}
& \varepsilon=\frac{\varepsilon_{h}-\varepsilon_{r a}}{\ln \left(\varepsilon_{h} / \varepsilon_{r a}\right)}, \\
& \varepsilon_{h}=\left[1+\left(\frac{1-x}{x}\right)\left(\frac{\rho_{v}}{\rho_{l}}\right)\right]^{-1} \text {, } \\
& \varepsilon_{r a}=\frac{x}{\rho_{v}}\left(\begin{array}{l}
{[1+0,12(1-x)]\left[\frac{x}{\rho_{v}}+\frac{1-x}{\rho_{l}}\right]} \\
\frac{1,18(1-x)\left[g \sigma\left(\rho_{l}-\rho_{v}\right)\right]^{0,25}}{G \rho_{l}^{0,5}}
\end{array}\right)^{-1} .
\end{aligned}
$$

Границю стратифікованого режиму визначають за залежністю

$$
G_{s t r a t}=\left\{\frac{226,2 A_{l d} A_{v d}^{2}\left(\rho_{l}-\rho_{v}\right) \mu_{l} g \cos \varphi}{x^{2}(1-x) \pi^{3}}\right\}^{\frac{1}{3}},
$$

де $A_{v d}, A_{l d}$ - відповідно геометричні площі пари та рідини двофазного потоку в трубі (рис. 2) розраховують за залежностями

$$
\begin{aligned}
& A_{v d}=A \varepsilon / d_{i}^{2} ; A_{l d}=A(1-\varepsilon) / d_{i}^{2} ; \\
& A_{l d}=1 / 8\left[\left(2 \pi-\theta_{\text {strat }}\right)-\sin \left(2 \pi-\theta_{\text {strat }}\right)\right] .
\end{aligned}
$$

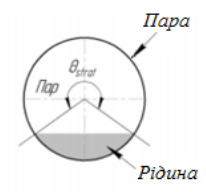

Рисунок 2. Геометричні розміри двофазного потоку в горизонтальній трубі

Кут стратифікації оцінюють (похибка $\approx 0,00005$ радіан для $2 \pi \geq \theta_{\text {strat }} \geq 0$ ) за формулою (14) з робіт [7]

$$
\theta_{\text {strat }}=2 \pi-2\left\{\begin{array}{l}
\pi(1-\varepsilon)+(3 \pi / 2)^{1 / 3}\left[1-2(1-\varepsilon)+(1-\varepsilon)^{1 / 3}-\varepsilon^{1 / 3}\right] \\
\frac{1}{200}(1-\varepsilon) \varepsilon\left[1+4\left((1-\varepsilon)^{2}+\varepsilon^{2}\right)\right]
\end{array}\right\} \text {. }
$$

\section{4. Аналітичний метод Sarma et. al [8]}

У роботі [8] запропоновано аналітичний метод розрахунку кутів рівня потоку під час двофазної однокомпонентної розшарованої течії в горизонтальній трубі за наявності й відсутності масообміну. Аналіз обмежується варіантом адіабатичної течії.

У роботі розглянуто два режими течії потоку: перший - режим турбулентної течії рідини і турбулентної течії пари, другий - режим ламінарної течії рідини i турбулентної течії пари. Для кожного з цих режимів автори наводять рівняння для розрахунку кута рівня потоку в трубі.

Під час турбулентної течії рідини і турбулентної течії пари пропонують таку залежність:

$$
\frac{\alpha_{1}}{\alpha_{2}}\left(\frac{\mu_{l}}{\mu_{v}}\right)^{0,2} \frac{\rho_{v}}{\rho_{l}}\left(\frac{1-x}{x}\right)^{1,8}=\left(\frac{\pi-\psi}{\psi}\right)^{1,2}\left[\frac{\psi-\frac{1}{2} \sin 2 \psi}{\pi-\psi-\frac{1}{2} \sin 2 \psi}\right]^{3},
$$

де $\alpha_{1}, \alpha_{2}-$ формфактори, що враховують нерівномірність дотичних напружень на стінці, $\psi$ - половина кута рівня потоку (рис. 3).

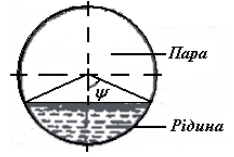

Рисунок 3- Половинний кут рівня потоку $\psi$

Під час ламінарної течії рідини і турбулентної течії пари запропонована залежність:

$$
139,2 \frac{\alpha_{1}}{\alpha_{2}}\left(\frac{\mu_{l}}{\mu_{v}}\right)^{0,2} \frac{\rho_{v}}{\rho_{l}} \frac{1-x}{x^{1.8}} \frac{1}{\operatorname{Re}_{s}^{0,8}}=\frac{(\pi-\psi)^{1,2}}{\psi^{2}}\left[\frac{\psi-\frac{1}{2} \sin 2 \psi}{\pi-\left(\psi-\frac{1}{2} \sin 2 \psi\right)}\right]^{3},
$$

де $\alpha^{{ }_{1}}{ }_{1}$ - формфактор, $\operatorname{Re}_{s}=4 G /\left(\lambda d_{i} \mu_{l}\right)$ - число Рейнольдса; $G$ - масова витрата.

На підставі рівнянь (15) та (16) побудовано криві залежностей між кутами рівня потоку та масового паровмісту для холодоагенту $R 12\left(T_{s}=316,5 \mathrm{~K}, G=\right.$ 28,5 кг/год, $d_{i}=0,0158$ мм) та повітряно-водяних сумішей за атмосферних умов, які подано у графічному вигляді. Водночас у роботі на графіку наведено чутливість рівнянь до змін значень $\alpha_{1} / \alpha_{2}$ та $\alpha^{6}{ }_{1} / \alpha_{2}$. За умови течії, що прийняти для висновку рівнянь (15) і (16), як для холодоагенту $R 12$, так і для повітряно-водяних сумішей методом припасування на графіку обирається крива, яка найбільш підходить для конкретного випадку (прикладу, варіанту, типу), та відповідає відношенню формфакторів $\alpha / \alpha_{2}=0,9$ i $\alpha^{6}{ }_{1} / \alpha_{2}=1,1$.

1.5. Фізична модель двофазного однокомпонентного потоку Rafer, Kezios [9]

Автори праці [9] побудували фізичну модель розшарованого двофазного потоку 3 кільцевою ламінарною плівковою конденсацією, а також проаналізували еквівалентну математичну модель.

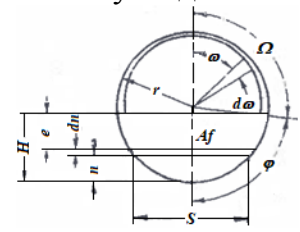

Рисунок 4. Геометрія потоку

На підставі збереження маси, енергії та кількості руху виведено рівняння, що визначає нахил поверхні поділу пара - рідина за довжиною труби:

$$
\begin{aligned}
& \frac{d \varphi}{d z}=\frac{\rho_{l} f_{L G}(\varphi-1 / 2 \sin 2 \varphi)^{3} / \rho_{L G}-\pi^{2} \varphi(1-x)^{2} f_{l}}{N_{1} r \cos \zeta \sin \varphi(\varphi-1 / 2 \sin 2 \varphi)^{3}-N_{2}(1-x)^{2} \sin ^{2} \varphi}- \\
& -\frac{N_{2}(1-x)(\varphi-1 / 2 \sin 2 \varphi)(d x / d z)-N_{1} \sin \zeta(\varphi-1 / 2 \sin 2 \varphi)^{3}}{N_{1} r \cos \zeta \sin \varphi(\varphi-1 / 2 \sin 2 \varphi)^{3}-N_{2}(1-x)^{2} \sin ^{2} \varphi} ;
\end{aligned}
$$

де $N_{1}=g \pi^{2} \rho_{l}^{2} r^{5} / \dot{m}^{2}$ та $N_{2}=2 \beta \pi^{2} r$, швидкість конденсації $d x / d z$ визначають за рівнянням

$$
-\frac{d x}{d z}=\frac{2}{\dot{m}}\left[\frac{g \rho_{l}\left(\rho_{l}-\rho_{v}\right) \lambda_{l}^{3}(\Delta t)^{3} R^{3}}{3 \mu_{l} r^{3}}\right]^{1 / 4}(\cos \zeta)^{1 / 4}\left[\frac{4}{3} \int_{0}^{\Omega} \sin ^{1 / 2} \omega d \omega\right]^{3 / 4} .
$$


Початковою умовою, необхідною для розв'язання рівняння (17), є дослідження течії у точці, де швидкість конденсації дорівнює нулю: $d x / \mathrm{dz}=0 ; d \phi / d z=0$.

Умова $d \phi / d z=0$, тобто постійність рівня потоку за умови відсутності конденсації, задовольняється в тому разі, якщо гальмування пари і поверхні розділу парарідина дуже мале. Розв'язання рівняння (17) для граничних умов $d x / \mathrm{dz}=0$ і $d \phi / d z=0$ щодо половинного кута потоку $\phi_{0}$, який за взятих припущень виявляється постійним, для горизонтальної труби є таким:

$$
\frac{\left(\varphi_{0}-1 / 2 \sin 2 \varphi_{0}\right)^{3}}{\varphi_{0}}=\pi^{2} \frac{\rho_{t p}}{\rho_{l}} \frac{f_{l}}{f_{t p}}(1-x)^{2},
$$

де $\rho_{t p}$ - густина суміші, яку знаходяться за залежністю $\rho_{t p}=\rho_{l} y+\rho_{v}(1-y)$, обємна частка $\gamma$ визначається відповідноза обємних витрат рідини та газу $y=V_{l} /\left(V_{l}+V_{g}\right)$.

Під час турбулентного потоку рідини та турбулентного потоку пари відношення коефіцієнтів тертя дорівнює

$$
\frac{f_{l}}{f_{t p}}=\frac{\alpha}{\alpha_{1}}\left[\frac{\varphi_{0}}{\pi} \frac{1}{(1-x)} \frac{\mu_{l}}{\mu_{t p}}\right]^{1 / 4},
$$

де $\alpha$ i $\alpha_{1}-$ поправкові коефіцієнти для рідини і пари відповідно, які враховують розподіл швидкостей; $\mu_{t p}$ динамічна в'язкість, яку розраховують за формулою $\mu_{t p}=\mu_{l} y+\mu_{v}(1-y)$

Під час підстановки рівняння (19) у рівняння (18) половинний кут рівня потоку стає незалежним від масової витрати $m$ та внутрішнього радіуса труби $R$.

Коли потік рідини є ламінарним, а потік пари - турбулентним, відношення коефіцієнтів тертя таке:

$$
\frac{f_{l}}{f_{t p}}=120 \frac{\varphi_{0}}{\pi^{1 / 4}} \frac{\alpha_{2}}{(1-x) \alpha_{1}}\left(\frac{R}{\dot{m}}\right)^{3 / 4} \frac{\mu_{l}}{\mu_{t p}^{1 / 4}},
$$

де $\alpha_{2}$ - поправковий коефіцієнт під час ламінарного потоку рідини, що враховує розподіл швидкостей.

Під час підстановки рівняння (20) у рівняння (18) половинний кут рівня потоку залежить від масової витрати $m$ та радіуса труби $R(R / m)$.

Оскільки для умов задачі, що розглядається, було мало відомо стосовно коефіцієнтів розподілу швидкостей та їх відношенні, автори для розрахунків запропонували взяти їх значення такими, що дорівнюють одиниці.

\section{6. Залежності Faghri, Zhang [10]}

У книзі [10] наведено спрощену кореляцію щодо розрахунку середнього коефіцієнта тепловіддачі

$$
\bar{\alpha}=\frac{\theta_{\text {strat }}}{\pi} \alpha_{d},
$$

де тепловіддачу $\alpha_{d}$ розраховують за залежністю

$$
\alpha_{d}=0,728 \frac{\pi}{\theta_{\text {strat }}} \varepsilon^{3 / 4}\left[\frac{g \rho_{l}\left(\rho_{l}-\rho_{v}\right) \lambda_{l}^{3} r}{\mu_{l} d}\right]^{1 / 4},
$$

об’ємний паровміст $\varepsilon-$ за формулою Zivi [11]

$$
\varepsilon=\left[1+\frac{1-x}{x}\left(\frac{\rho_{v}}{\rho_{l}}\right)^{2 / 3}\right]^{-1},
$$

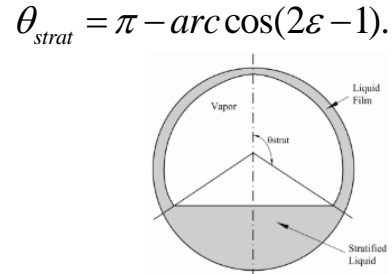

Рисунок 5. Поперечний переріз труби під час стратифікованої течії

\section{7. Механістичні моделі конденсації}

Останнім часом 3'явилися моделі течії двох і більше робочих тіл, які грунтуються на використанні рівнянь нерозривності спільно з рівняннями збереження енергії, що описують взаємодію фаз для різних режимів течії, які називають механістичними моделями багатофазних течій.

Механістичне моделювання багатофазних течій, двох або більше робочих тіл є найбільш загальним і повним. Сенс моделі полягає у виокремленні фаз або їх частин у самостійні потоки, які взаємодіють як із трубою, так і один з одним. Фази можуть протікати з різною швидкістю різними частинами перерізу труби і навіть не перебувати в рівновазі. При цьому для кожної 3 виділених фаз у загальному варіанті необхідно записати рівняння нерозривності, збереження кількості руху та енергії, з урахуванням взаємодії зі стінками труби та іншими фазами.

1.7.1. Механістична модель конденсації $з$ кодом RELAP5 для горизонтальних труб і труб 3 нахилом Szijártóa, Freixa [12]

У роботі наведено модель конденсації в горизонтальній і трубі з невеликим нахилом із модифікованим кодом RELAP5. У дослідженні основну увагу приділено процесам теплообміну під час конденсації в середині горизонтальної та дещо нахиленої труби за моделлю коду RELAP5/mod3.3.

У ядерній промисловості переважають розмірні системні коди задля моделювання всіх критеріїв атомної промисловості та для аналізу безпеки надійності систем безпеки.

Розрахунковий комп'ютерний код RELAP5 широко застосовують у процесі підготування матеріалів аналізу безпеки AEC, щоб оцінити виконання критеріїв безпеки під час нормальної експлуатації, їх порушень під час експлуатації та в разі аварій. У коді RELAP5 містяться внутрішні вбудовані модулі, зокрема модуль теплогідравлічної системи стосовно прогнозування перехідних процесів конденсації, що швидко змінюються.

Автори роботи, враховуючи недоліки перехідних процесів теплообміну в разі швидкого процесу конденсації на стінці труби, запропонували модифіковану модель конденсації в середині горизонтальних труб. Класична продуктивність коду була поліпшена механістичною моделлю конденсації, яка враховує вплив стратифікованої геометрії потоку та локального об'ємного паровмісту. Зіставлення зміненого коду RELAP5/mod3.3 з оригінальним кодом RELAP5 показало, що покращене прогнозування процесу тепловіддачі було досягнуто завдяки врахуванню розподілу температури, тиску і розподілу об'ємного паровмісту вздовж горизонтальної труби під час конденсації. 
Середнє значення коефіцієнта тепловіддачі розраховують як середнєзважене, з урахуванням кута стратифікації, за аналогічною формулою з роботи [4]:

$$
\alpha_{\text {average }}=\frac{\alpha_{f} \Phi_{\text {strat }}+\alpha_{s}\left(2 \pi-\Phi_{\text {strat }}\right)}{2 \pi},
$$

де $\alpha_{f}$ плівки розраховують, з деякими припущеннями, за теорією Нуссельта з введенням у залежність кута нахилу труби $\theta$ :

$$
\alpha_{f}=2^{3 / 4}\left[\frac{\rho_{l}\left(\rho_{l}-\rho_{v}\right) g \cos \theta r \lambda_{l}^{3}}{2 \mu_{l}\left(T_{\text {sat }}-T_{\text {wall }}\right) R}\right]^{1 / 4} \frac{2}{\Phi_{\text {strat }}} \int_{0}^{\Phi_{\text {stuat }}}\left[\frac{\sin \phi}{\phi}\right]^{1 / 4} d \phi,
$$

де $\theta$ - кут нахилу труби (рад); $\Phi_{\text {strat }}-$ кут стратифікації (рад). [8].

Тепловіддачу $\alpha_{s}$ розраховують за залежністю (8),

Якщо об'ємний паровміст $\varepsilon<0,5$, то кут стратифікації можна оцінити за формулою, розробленою у праці [11] згідно з геометричними характеристиками потоку (рис. 6):

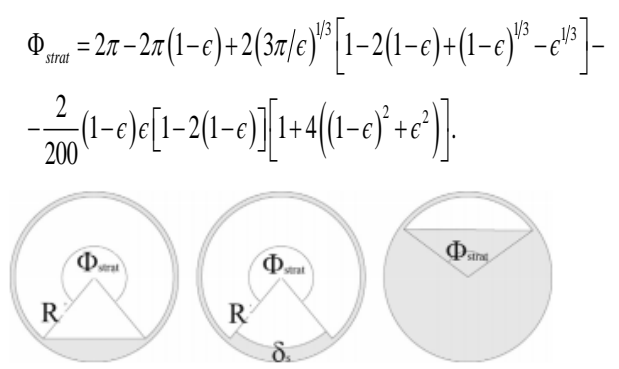

Рисунок 6. Модель стратифікованого потоку з відповідною геометрією

Товщину плівки рідини розраховують за різних значень об'ємного паровмісту $\varepsilon$ у такий спосіб:

- якщо $\varepsilon>0,5$,

$$
\delta_{s}=R-\left[R^{2}-\frac{2 A_{L}^{\text {bottom }}}{2 \pi-\Phi_{\text {strat }}}\right],
$$

де $A_{L}^{\text {bottom }}=R^{2}\left[\pi-\frac{\Phi_{\text {strat }}-\sin \Phi_{\text {strat }}}{2}\right]$;

- якщо $\varepsilon<0,5, \delta_{s}=R+R \cos \left(\Phi_{\text {strat }} / 2\right)$.

1.7.2. Механістична модель конденсації Ahn., Yun [13-15].

У роботі запропоновано нову механістичну конденсаційну модель щодо пасивної безпеки допоміжної системи живильної води (passive auxiliary feedwater system (PAFS)) корейської сучасної атомної електростанції APR+ (Power Reactor Plus), що містить конденсаційний теплообмінник, який має майже горизонтальні трубки (нахил $3^{\circ}$ ).

У наявних експериментальних дослідженнях та більшості кореляцій емпіричного типу недооцінюють коефіцієнт тепловіддачі в горизонтальних трубах конденсаційних теплообмінників, аналогічних до PAFS. Як альтернативний підхід до досягнення найкращого прогнозу використовують механістичну модель конденсації, яка дозволяє опрацювати два різних механізми тепловіддачі в окремих режимах течії, які зазвичай спостерігаються у трубах теплообмінника PAFS. За такого підходу оцінювання об'ємного паровмісту має важливе значення для розгляду різних механізмів теплообміну в майже горизонтальній конденсаційній трубі. Розроблення нової механістичної моделі для передба- чення об'ємного паровмісту в розділених потоках зосереджено на безперервні зміни геометричної форми фаз потоку та коефіцієнт тертя під час фазового переходу. Отже, геометричні зв'язки, які передбачали ідеальну дугу відносно вигнутих міжфазних поверхонь, безперервно використовували для визначення режимів переходу від стратифікованого до кільцевого потоків. Окрім того, водночас вивчали міжфазний коефіцієнт для кожного з режимів течії фаз.

Модель побудована на основі балансу двофазного імпульсу рівняння для охоплення різних видів рідин, умов течії та кутів нахилу проточного каналу в відокремленому потоці. Об'ємний паровміст розраховують без будь-якої відсутності безперервності під час переходів режиму потоку, при цьому розглядають безперервні зміни міжфазних геометричних характеристик та міжфазних коефіцієнтів тертя у трьох типових відокремлених потоках, а саме стратифіковано-гладкому, стратифіковано-хвильовому та кільцевому потоках (рис. 7).

За висновками авторів роботи, порівняння розрахунків за запропонованою моделлю з отриманими експериментальними даними різних авторів, що стосуються різних типів рідин та режимів течії, показало задовільне узгодження.

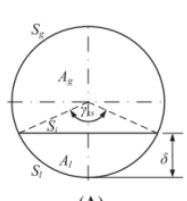

(A)

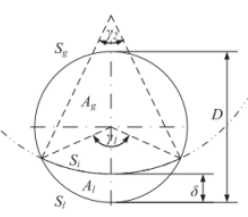

(B)

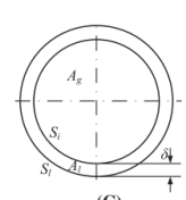

(C)
Рисунок 7. Ідеальні міжфазні форми відокремлених режимів потоку в горизонтальній трубі: $A$ - стратифіковано-гладкий; $B$ - стратифіковано-хвильовий; $C$ - кільцевий

\subsubsection{1. Стратифіковано-гладкий режим}

Згідно зі стратифіковано-гладким режимом потоку (рис. 7) об'ємний паровміст розраховують за формулою

$$
\varepsilon=1-\frac{\gamma_{1}-\sin \gamma_{1}}{2 \pi} .
$$

Кут затоплення $\gamma_{1}$ можна розрахувати неявно за допомогою ітераційної процедури $\left(\gamma_{1}=\pi-\arcsin (2 \varepsilon-1)\right)$ або явно - апроксимацією формули з праці [7] таким чином:

$$
\begin{aligned}
& \theta_{s s}=2 \pi(1-\varepsilon)+2\left(\frac{3 \pi}{2}\right)^{1 / 3}\left[2 \varepsilon-1+(1-\varepsilon)^{1 / 3}-\varepsilon^{1 / 3}\right]- \\
& -\frac{1}{100} \varepsilon(1-\varepsilon)(2 \varepsilon-1)\left[1+4\left((1-\varepsilon)^{2}+\varepsilon^{2}\right)\right] .
\end{aligned}
$$

\subsubsection{2. Стратифіковано-хвильовий режим}

Згідно зі стратифіковано-хвильовим режимом потоку (рис. 7) змочений кут затоплення, який є необхідним параметром для обчислювання периметра контактної стінки, розраховують за залежністю, запропонованою Hart [16]:

$$
\begin{aligned}
\gamma_{1} & =2 \pi\left(0,52(1-\varepsilon)^{0,374}+0,26 F r^{0,58}\right), \\
\text { де число } F r & =\frac{\rho_{l} w_{l}^{2}}{\left(\rho_{l}-\rho_{g}\right) D g \cos \theta_{i n c}} .
\end{aligned}
$$

На відміну від формули, використаної у роботі [16], до розрахунку критерію $F r$ додано кут нахилу $\theta_{i n c}$, 
який ураховує орієнтацію потоку в трубі до лінії горизонту.

Об'ємний паровміст $\varepsilon$ відповідно до стратифіковано-хвильового режиму розраховують за рівнянням:

$$
\varepsilon=1-\frac{\gamma_{1}-\sin \gamma_{1}}{2 \pi}+\frac{\gamma_{2}-\sin \gamma_{2}}{2 \pi}\left(\frac{1-\cos \gamma_{1}}{1-\cos \gamma_{2}}\right) .
$$

\subsubsection{3. Модель конденсації}

У роботі [13] розроблено новий пакет моделей розрахунку тепловіддачі під час конденсації пари в середині труби задля поліпшення здатності прогнозування одномірного коду оцінювання безпеки в майже горизонтальній трубі. Новий пакет моделей складається 3 одновимірної моделі збереження залишкового імпульсу, моделі передбачення форми інтерфейсу, моделі прогнозування режиму потоку та моделі розрахунку коефіцієнта тепловіддачі.

Модель розрахунку коефіцієнта тепловіддачі під час конденсації складається з моделі конвективної тепловіддачі та моделі плівкової конденсації, яка враховує вплив міжфазної напруги зсуву, що виникає в результаті високого конвективного потоку пари. 3 огляду на це модель може механічно враховувати явища теплообміну, які генеруються у верхній і нижній частинах труби в умовах розділення потоку. Розроблений пакет моделей теплообміну під час конденсації оцінювали та перевіряли, використовуючи наявні експериментальні дані, отримані у горизонтальних та майже горизонтальних трубах за умови конденсації в них водяної пари. 3 кількісного погляду результати оцінювання підтвердили поліпшення прогнозних показників за новим пакетом моделі розрахунку тепловіддачі.

Отже, середню тепловіддачу, що складається 3 кореляцій розрахунку плівкової конденсації для верхньої частини i розрахунку конвективного теплообміну в нижній частині майже горизонтальної труби, розраховують за рівнянням

$$
\alpha_{\text {average }}=\frac{\alpha_{\text {film }}\left(2 \pi-\gamma_{1}\right)+\alpha_{\text {convective }} \gamma_{1}}{2 \pi},
$$

де

$$
\alpha_{\text {film }}=0,729\left(1+8,7 \cdot 10^{-4} \operatorname{Re}_{g}^{0,47}\right)\left(\frac{\rho_{l}\left(\rho_{l}-\rho_{v}\right) g r \lambda_{l}^{3}}{\mu_{l} D\left(T_{\text {sat }}-T_{w}\right)}\right)^{1 / 4} ;
$$

$\alpha_{\text {convective }}$ розраховують за модифікованою формою рівняння $з$ праці [17]:

$$
\alpha_{\text {convective }}=0,023 \operatorname{Re}_{l}^{0,8} \operatorname{Pr}_{l}^{0,4}\left(\frac{\lambda_{l}}{D_{h l}}\right),
$$

де $D_{h l}=4 A_{l} / S_{l} \quad-\quad$ гідравлічний діаметр; $A_{l}=\frac{R^{2}}{2}\left[\gamma_{l}-\sin \gamma_{l}\right]-$ площа труби, затоплена струмком конденсату; $S_{l}=\gamma_{l}(D / 2)$ - периметр контакту струмка зі стінкою труби.

\section{II. ЕМПІРІЧНІ МЕТОДИ РОЗРАХУНКУ ТЕ- ПЛООБМІНУ ТА КУТА ЗАТОПЛЕННЯ ПЕРЕРІЗУ ТРУБИ КОНДЕНСАТОМ}

У дисертації Ширяєва [18] досліджував теплообмін під час конденсації холодоагентів $R 12, R 22, R 502$ та $R 717$ у середині горизонтальних труб і змійовиків. За результатами досліджень автор пропонує брати середнє значення половини кута затоплення фо таким, що дорівнюе $60^{\circ}$.

2.1. Розрахунок теплообміну та кута затоплення 3 роботи Кректунова [19]

2.1.1. Розрахунок кута затоплення

Автори роботи [19], на підставі експериментальної залежності для дійсного об'ємного паровмісту під час стратифікованої структури течії повітряно-водяної суміші з роботи [20] та дослідних даних роботи [21], запропонували таку апроксимаційну залежність розрахунку кута затоплення:

$$
\phi_{0}=\left\{\begin{array}{c}
1,86 \chi^{0,146} 3 a 0 \leq \chi \leq 0,2 ; \\
1,36(1+\chi)^{0,36} \text { 3a } 0,2<\chi \leq 1 .
\end{array}\right\},
$$

де $\chi=\frac{F r_{1} \lambda}{2 \sin \beta}-$ відносний коефіцієнт; $F r_{l}-$ критерій Фруда, який розраховують за зведеною швидкістю рідини; $\lambda_{l}-$ коефіцієнт гідравлічного опору; $\beta-$ кут нахилу поздовжньої осі труби до лінії горизонту.

Розрахунки авторів [19] кута затоплення за формулою (2) показали дещо нижчі значення, ніж отримані за формулою (4), де швидкості пари не враховували (за значенням числа $R e=100$ розбіжність становила 2,6 \%, за $R e=700-9,1 \%)$.

Також у роботі [19], на основі експериментальних даних роботи [22], під час конденсації пари в середині горизонтальної труби, в якій було встановлено, що об'ємний паровміст можна визначати за формулою (22), було отримано ще одне рівняння для розрахунку кута затоплення:

$$
\theta=1,86\left[1+\frac{x}{1-x}\left(\frac{\rho_{l}}{\rho_{v}}\right)\right]^{-0,36},
$$

де $x$ - масовий паровміст.

\subsection{2. Розрахунок теплообміну $[19 ; 23]$}

У роботі [23] наведено залежність для розрахунку конденсації в горизонтальній трубі за такою залежністю:

$$
\alpha=\left[\alpha_{F}^{m}+\alpha_{i}^{m}\right]^{1 / 4}(m=4),
$$

де $\alpha_{F}$ - локальне значення коефіцієнта тепловіддачі під час конденсації пари в горизонтальній трубі за режимом пари, яка швидко рухається, розраховують за формулою:

$$
\alpha_{F}=\frac{\lambda_{f}}{\delta} \sqrt{1+\left(k \operatorname{Re}_{f}^{0,8} \operatorname{Pr}_{f}^{0,8}\left(1+0,5 \frac{\tau_{\delta}}{\tau_{w f}}\right)\right)^{2}},
$$

у якій коефіцієнт $k=6,5 \times 10^{-3}$, відношення дотичного напруження $\tau_{\delta}$ на межі пара - рідина за умови конденсації пари, тобто з урахуванням поперечного потоку маси, до дотичного напруження, розрахованого за стандартною методикою:

$$
\left(\frac{\tau_{\delta}}{\tau_{w f}}\right)^{1 / 2}=1+1,22 X_{t t}^{0,2} .
$$

Локальне значення коефіцієнта тепловіддачі $\alpha_{i}$ під час конденсації нерухомої пари у формулі (30) розраховують за залежністю Нуссельта.

\section{2. Залежність Кутателадзе [24]}

У роботі [24] експериментально досліджували гідродинаміку течії води в напівкруглих горизонтальних 
каналах. На підставі отриманих експериментальних даних було запропоновано емпіричну залежність для визначення кута затоплення труби конденсатом:

$$
\frac{U}{\pi D}=12,84\left(\frac{U v_{l}^{3}}{g^{2} d_{i}^{7}}\right)^{0,12}
$$

де $U$ - периметр нижньої частини труби, змочений струмком конденсату.

У праці [19] для холодоагенту $R 12$ наведено порівняння розрахунків кута затоплення за формулами (32) та (4) залежно від Re. Результати розрахунків за формулою (4) виявилися суттєво вищими від розрахунків за формулою (32) (за значенням числа $R e=100$ розбіжність становила $45,3 \%$, за $R e=1000-38,6 \%$ ).

\section{ІІІ. ЕМПІРИЧНІ МЕТОДИ РОЗРАХУНКУ ТЕП- ЛООБМІНУ ТА КУТА ЗАТОПЛЕННЯ ПЕРЕРІЗУ ТРУБИ КОНДЕНСАТОМ ПІД ЧАС СТРАТИФІ- КОВАНОГО-ХВИЛЬОВОГО РЕЖИМУ ТЕЧІЇ ФАЗ}

\section{1. Емпірична залежність Dobson, Chato [25]}

У poботі Dobson, Chato [25] наведено емпіричну залежність для розрахунку тепловіддачі під час стратифіковано-хвильового режиму течії у такому вигляді

$$
\begin{aligned}
& \qquad N u=\frac{\alpha d}{\lambda_{l}}=\frac{0,23 \operatorname{Re}_{g o}^{0,12}}{1+1,11 X_{t t}^{0,58}}\left[\frac{G a_{l} \operatorname{Pr}_{l}}{J a_{l}}\right]^{0,25}+\left(1-\frac{\theta_{\text {strat }}}{\pi}\right) N u_{\text {forced }}, \quad \text { (33) } \\
& \text { де } \quad \operatorname{Re}_{g o}=G d_{i} / \mu_{g}, \quad G a=\rho_{l}\left(\rho_{l}-\rho_{v}\right) g d^{3} / \mu_{l}^{2} ; \\
& J a_{l}=r / c_{p} \Delta T ; \quad X_{t t}=\left(\mu_{l} / \mu_{v}\right)^{0,1}\left(\rho_{v} / \rho_{l}\right)^{0,5}[(1-x) / x]^{0,9}, \\
& \operatorname{Pr}=c_{p} \mu / \lambda / .
\end{aligned}
$$

У нижній частини труби теплообмін розраховують за залежністю

$$
N u_{\text {forced }}=0,0195 \operatorname{Re}_{l}^{0,8} \operatorname{Pr}_{l}^{0,4}\left(1,376+\frac{c_{1}}{X_{t t}^{c_{2}}}\right)^{1 / 2} .
$$

У формулі (34) $c_{1}$ і $c_{2}$ - константи: за значеннями $0<\quad F r \quad<0,7 \quad\left(F r_{l}=G^{2} /\left(d^{2} g \rho_{l}\right)\right) \quad$ розраховують $c_{1}=4,172+5,48 F r_{l}-1,564 F r_{l}^{2}, c_{2}=1,773-0,169 F r_{l}$, для значень $F r>0,7$ дорівнюють $-c_{1}=7,242$ і $c_{2}=1,655$.

Кут плівки $\theta_{\text {strat }}$ розраховують за залежністю

$$
\theta_{\text {strat }}=\pi-\arccos (2 \varepsilon-1) .
$$

Об'ємний паровміст $\varepsilon$, що входить до складу формули (35) розраховують за рівнянням (22).

3.2. Емпірична модель конденсації теплообміну Singh et al. [26]

У роботі [26] проводили досліди під час конденсації холодоагенту $R 134 a$ в середині гладкої мідної труби iз зовнішнім діаметром $d_{\text {out }}=12,7$ мм. Досліджували квазілокальні коефіцієнти тепловіддачі $\alpha$ за низькими значеннями масових швидкостей $G$. Умови досліджень було підібрано таким чином, щоб двофазний потік у дослідній дільниці відповідав стратифікованохвильовому режиму. Встановлено, що коефіцієнт тепловіддачі залежить як від теплового потоку, так і від рівня потоку конденсату.

На підставі результатів дослідів пропонують нову кореляцію, відповідно до якої загальний коефіцієнт тепловіддачі $є$ сумою коефіцієнтів тепловіддачі, що зумовлено утворенням плівки у верхній частині труби та примусовою конвекцією у нижній частині труби. Нова модель розрахунку тепловіддачі має такий вигляд:

$$
\alpha=\theta \alpha_{b o t}+(2 \pi-\theta) \alpha_{t o p},
$$

де $\theta$ - кут у радіанах, що стягує верхню дугу частини трубки до рівня рідини (кут рівня рідини) та приблизно дорівнює

$$
\theta \approx 2 \cos ^{-1}(2 \varepsilon-1)
$$
ють як

Коефіцієнт тепловіддачі знизу плівки $\alpha_{b o t}$ оціню-

$$
\alpha_{b o t}=\alpha_{l}\left(1+\frac{0,2332}{X_{t t}^{1,402}}\right),
$$

де $\alpha_{l}-$ коефіцієнт тепловіддачі для частини потоку рідини у трубі.

За значеннями чисел Рейнольдса, більших ніж $R e>$ $2300, \alpha_{l}$ розраховують за рівнянням із роботи [27] у турбулентному потоці:

$$
N u=\frac{\left(C_{f} / 8\right)(\mathrm{Re}-1000) \operatorname{Pr}}{1,07+12,7 \sqrt{C_{f} / 8}\left(\operatorname{Pr}^{2 / 3}-1\right)},
$$

де коефіцієнт тертя $C_{f}$ розраховують за формулою 3 праці [28] $C_{f}=(0,79 \ln \mathrm{Re}-1,64)^{-2}$ або за формулою 3 праці [29] $C_{f}=\left[1,82 \cdot \log _{10}(\operatorname{Re})-1,64\right]^{-2}$.

Для більш низьких значень чисел Рейнольдса $R e<$ $2300 \alpha_{l}$ розраховують за рівнянням (28) 3 праці [17].

Коефіцієнт тепловіддачі у верхній частині труби $\alpha_{\text {top }}$ розраховують за залежністю 3 аналітичної моделі тепловіддачі Chato [30] під час конденсації плівки під впливом сили тяжіння, згідно з якою тепло, що передається крізь струмок конденсату, нехтовно порівняно 3 провідністю у тонкий плівці конденсату верхньої частині труби:

$$
\alpha_{\text {top }}=0,728 K_{C}\left[\frac{g \rho_{l}\left(\rho_{l}-\rho_{v}\right) \lambda_{l}^{3} r^{\prime}}{\mu_{l}\left(T_{\text {sat }}-T_{\text {wall }}\right) D}\right]^{1 / 4},
$$

де теплоту конденсації $r^{\prime}$ визначено за аналізом Chato [30] такою, що дорівнює

$$
r^{\prime}=r\left[1+0,68 \frac{c_{p, l}\left(T_{\text {sat }}-T_{\text {wall }}\right)}{r}\right] .
$$

Значення $K_{C}$ у формулі (40) дорівнює $K_{C}=0,1271$.

\section{ВИСНОВКИ}

1. Проаналізовано моделі та методики розрахунку кута затоплення труби струмком конденсату, а також розрахунку тепловіддачі за гравітаційним режимом течії в середині горизонтальних труб.

2. Аналіз показав, що емпіричні кореляції, отримані на основі узагальнення експериментальних даних, мають характерні, тільки їм притаманні особливості. 3 огляду на це залежності придатні для використання лише у вузькому діапазоні змінювання режимних параметрів.

3. У подальших роботах необхідно провести розрахунки гідродинаміки й тепловіддачі за наведеними залежностями, щоб порівняти результати досліджень різних авторів, виявити оптимальні розрахункові залежності у разі гравітаційного режиму течії потоку. 


\section{Література}

1. Nusselt W. Die Oberflächenkondensation des Wasserdampfes. Zeitschrift // VDI. - Germany, 1916. - № 60. - P. 541-546, 568-575.

2. Консетов В. В. К вопросу о теплоотдаче при конденсации пара внутри горизонтальных труб // Изв. Вузов. Энергетика. -Вып. 12. - М., 1961.

3. Консетов В. В. Исследование теплоотдачи при конденсации чистого насыщенного пара внутри труб: автореф. канд. дис. - Л.: ВВМОЛУ им. Ф. Э. Дзержинского, 1962. - 17 c.

4. El Hajal J., Thome J. R., Cavallini A. Condensation in horizontal tubes. Part 1: Two-phase flow pattern map // International Journal of Heat and Mass Transfer. - 2003. № 46 (18). - P. 3349-3363.

5. Thome J. R., Hajal J., Cavallini A. Condensation in horizontal tubes. Part 2: New heat transfer model based on flow regimes // International Journal of Heat and Mass Transfer. - 2003. - V. 46. - № 18. - P. 3365-3387.

6. Rouhani S. Z. Subcooled void fraction. // Report No. AERTV841. AB Atomenergi Sweden. - 1969. - 138 p.

7. Biberg D. An explicit approximation for the wetted angle in two-phase strati-fied pipe flow. Can. J. Chem. Eng. 77, 1999. - P. 1221-1224.

8. Sarma P. K., Sarma A. S. P. and Apparao K. Venkata. Predictions of Flow-Level Angles in Two-Phase, OneComponent Stratified Flow // Journal. Heat Transfer. 1971. - V. 93. - № 2. - P. 254-255.

9. Rufer C., Kezios S. Analysis of two-phase one component stratified flow with condensation. ASHARE Trans. 88. - 1966. P. 265-272.

10. Faghri A., Zhang Y. Transport Phenomena in Multiphase Systems. Academic Press. 2006. 1064 p.

11. Zivi S. M. Estimation of steady-state steam voidfraction by means of the principle of minimum entropy production, Trans. ASME J. Heat Transfer. 86. - 1964. - P. 247-252.

12. R. Szijártóa, J. Freixa, H.-M. Prasser Simulation of condensation in a closed, slightly inclined horizontal pipe with a modified RELAP5 code. Nuclear Engineering and Design. 273. - 2014. - P. 288-297.

13. Ahn T.-H., Yun B.-J. and Jeong J.-J. Void fraction fraction prediction for separated flows in the nearly horizontal tubes. Nucl Eng Technol 47. - 2015. - P. 669-677.

14. Lee D., Ahn T., Yun B., Jeong J. J. Implementation of a New Condensation Heat Transfer Model into MARS-KS 1.3 / Transactions of the Korean Nuclear Society Autumn Meeting Gyeongju, Korea, October 26-27. - 2017.

15. Ahn T. H., Yun B. J., Jeong J. J., Kang K. H., Park Y.S., Cheon J., Jerng D. W. Development of a new condensation model for the nearly horizontal heat exchanger tube under the steam flowing conditions,
International / International Journal of Heat and Mass Transfer. - Vol. 79. - P. 876-884, 2014.

16. Hart J., Hamersma P. J., Fortuin J. M. H. Correlations predicting frictional pressuredrop and liquid holdup during horizontal gas-liquid pipe flowwith a small liquid holdup, International Journal of Multiphase Flow. - Vol. 15, no. 6. - p. $947 .-1989$.

17. Dittus F. W., Boelter L. M. K. University of California (Berkley) publications on engineering. - vol. 2. - Berkley (CA): University of California. - 1930. - p. 443.

18. Ширяев Ю. Н. Исследование теплообмена при конденсации фреонов и аммиака внутри горизонтальных труб и змеевиков: автореф. канд. дис.- Л.: ЛТИХП, 1974.- 24 c.

19. Кректунов О. П., Савус А. С. Процессы конденсации и конденсаторы масложирового производства.СПб.: АООТ «НПО ЦКТИ», -1998. - 495 с.

20. Мамаев В. А., Одишарин Г. Э., Семенов Н. И., Точигин А. А. Гидродинамика газожидкостных смесей в трубах. - М.: Недра, 1969.- 207 с.

21. Точигин А. А., Елин Н. Н., Арсенов В. Г. Влияние вязкости жидкой фазы на истинное газосодеожание и область существования расслоенного потока двухфазной смеси в слабонаклоненных трубах // ИФЖ. - 1983. - т. 65, № 2.- C. 217-221.

22. Kosky P. G. Thin Liquid Films Under Simultaneous Shear and Gravity Forces.- Int. J. HeatMassTransfer, 1971. - V. 14. - P. 1220-1224.

23. Безлепкин В. В., Сидоров В. Г., Иванова М. В., Кректунов О. П. Верификация и корректировка модели конденсации кода РАТЕГ/СВЕЧА/ГЕФЕСТ для цилиндрических каналов различной ориентации. - С. 1 - 11.

24. Кутателадзе С. С. Теплоотдача при пленочной конденсации пара внутри горизонтальной трубы. В кн.: Вопросы теплоотдачи и гидравлики двухфазных сред. М.: ГЭИ, 1961. - С. 138-156.

25. Dobson M., Chato J. 1998. Condensation in smooth horizontaltubes. J. Heat Transfer 120, 193-213, http://dx.doi.org/10.1115/1.2830043.

26. Singh A., Ohadi M. M. \& Dessiatoun S. V. (1996). Empirical Modeling of Stratified Wavy Flow Condensation Heat Transfer in Smooth Horizontal Tubes. ASHRAE Trans: Symposia, 9, 596-603.

27. Gnielinski V. New equations for heat and mass transfer in turbulent pipe and channel flow [Text] / V. Gnielinski // Int. Chem. Eng. 1976. - Vol. 16. - P. 359-368.

28. Петухов Б. С., Генин Л. Г., Ковалев С. А. Теплообмен в ядерных энергетических установках. - М.: Атомиздат, 1974. $-408 \mathrm{c}$.

29. Филоненко Г. К. Формула для коэффициента гидравлического сопротивления гладких труб/ В Сб. «Проблемы турбулентности». -М.: ОНТИ, 1936. - С. 8-9.

30. Chato J. C. (1962). Laminar Condensation Inside Horizontal and Inclined Tubes. ASHRAEJ, 4, 52-60. 


\title{
Hydrodynamics and heat transferin vapour condensing inside horizontal tubesat stratified phase flow. Review
}

\author{
V. V. Gorin ${ }^{1}$, V. V. Sereda ${ }^{2}$ \\ ${ }^{1}$ Odessa State Academy of Technical Regulation and Quality, Odessa \\ ${ }^{2}$ National University of Water Management and Nature Resources Use, Rivne
}

\begin{abstract}
The analysis of theoretical and experimental solutions for hydrodynamics and heat transfer prediction in condensing inside horizontal tubes at stratified flow is presented in this paper. It is shown, that theoretical models and methods have been submitted for two flow patterns: annular flow, when condensate film is flowing under friction forces, and gravitational (stratified) flow, when gravity dominates among the forces affecting condensate flow. Also, heat transfer by vapor condensing in a stream (bottom part of tube) is predicted by different correlations not proved by the experiments, but related to convective heat transfer in tube. The proposed empirical correlations for heat transfer prediction reveal significant discrepancies both in heat-transfer coefficients and in the rate of main parameters $\left(\operatorname{Re}_{l}, \operatorname{Re}_{v}, \operatorname{Pr}_{l}\right)$ that effect on condensation. In addition, there are often no remarks concerning boundaries for the use of the proposed relationships. The existing theoretical and experimental correlations for calculation of the flooding angle of a condensate stream in the bottom part of the tube at stratified and stratified-wave flow of the phases are systematized. In addition, solutions based on modern mechanistic models is given in this paper. These models use basic physical laws for flow characteristics simulation. Such models give a more precise definition for large quantity of geometrical parameters and thermophysical properties of working fluids. At first, mechanistic models determine the flow patterns. Further, according to the mechanics of chosen flow regime, hydrodynamic and heat transfer parameters are calculated. The necessity of new studies concerning search for optimum solutions for heat transfer prediction in condensing inside horizontal tubes at stratified flow is substantiated.
\end{abstract}

Keywords: Condensation; Heat exchange; heat transfer coefficient; Mathematical model; Flooding angle; Stratified flow.

\section{References}

1. Nusselt W. Die Oberflächenkondensation des Wasserdampfes. Zeitschrift // VDI. - Germany, 1916. - № 60. - P. 541-546, 568-575.

2. Консетов В. В. К вопросу о теплоотдаче при конденсации пара внутри горизонтальных труб// Изв. Вузов. Энергетика. -Вып. 12. - М., 1961.

3. Консетов В. В. Исследование теплоотдачи при конденсации чистого насыщенного пара внутри труб: автореф. канд. дис. - Л.: ВВМОЛУ им. Ф. Э. Дзержинского, 1962. - $17 \mathrm{c}$.

4. El Hajal J., Thome J. R., Cavallini A. Condensation in horizontal tubes. Part 1: Two-phase flow pattern map // International Journal of Heat and Mass Transfer. - 2003. № 46 (18). - P. 3349-3363.

5. Thome J. R., Hajal J., Cavallini A. Condensation in horizontal tubes. Part 2: New heat transfer model based on flow regimes // International Journal of Heat and Mass Transfer. - 2003. - V. 46. - № 18. - P. 3365-3387.

6. Rouhani S. Z. Subcooled void fraction. // Report No. AERTV841. AB Atomenergi Sweden. - 1969. - 138 p.

7. Biberg D. An explicit approximation for the wetted angle in two-phase strati-fied pipe flow. Can. J. Chem. Eng. 77, 1999. - P. 1221-1224.

8. Sarma P. K., Sarma A. S. P. and Apparao K. Venkata. Predictions of Flow-Level Angles in Two-Phase, OneComponent Stratified Flow // Journal. Heat Transfer. 1971. - V. 93. - № 2. - P. 254-255.

9. Rufer C., Kezios S. Analysis of two-phase one component stratified flow with condensation. ASHARE Trans. 88. - 1966. P. 265-272.

10. Faghri A., Zhang Y. Transport Phenomena in Multiphase Systems. Academic Press. 2006. 1064 p.
11. Zivi S. M. Estimation of steady-state steam voidfraction by means of the principle of minimum entropy production, Trans. ASME J. Heat Transfer. 86. - 1964. - P. 247-252.

12. R. Szijártóa, J. Freixa, H.-M. Prasser Simulation of condensation in a closed, slightly inclined horizontal pipe with a modified RELAP5 code. Nuclear Engineering and Design. 273. - 2014. - P. 288-297.

13. Ahn T.-H., Yun B.-J. and Jeong J.-J. Void fraction fraction prediction for separated flows in the nearly horizontal tubes. Nucl Eng Technol 47. - 2015. - P. 669-677.

14. Lee D., Ahn T., Yun B., Jeong J. J. Implementation of a New Condensation Heat Transfer Model into MARS-KS 1.3 / Transactions of the Korean Nuclear Society Autumn Meeting Gyeongju, Korea, October 26-27. - 2017.

15. Ahn T. H., Yun B. J., Jeong J. J., Kang K. H., Park Y.S., Cheon J., Jerng D. W. Development of a new condensation model for the nearly horizontal heat exchanger tube under the steam flowing conditions, International / International Journal of Heat and Mass Transfer. - Vol. 79. - P. 876-884, 2014.

16. Hart J., Hamersma P. J., Fortuin J. M. H. Correlations predicting frictional pressuredrop and liquid holdup during horizontal gas-liquid pipe flowwith a small liquid holdup, International Journal of Multiphase Flow. - Vol. 15, no. 6. - p. 947. - 1989 .

17. Dittus F. W., Boelter L. M. K. University of California (Berkley) publications on engineering. - vol. 2. - Berkley (CA): University of California. - 1930. - p. 443.

18. Ширяев Ю. Н. Исследование теплообмена при конденсации фреонов и аммиака внутри горизонтальных труб и змеевиков: автореф. канд. дис.- Л.: ЛТИХП, 1974.- 24 c. 
19. Кректунов О. П., Савус А. С. Процессы конденсации и конденсаторы масложирового производства.СПб.: АООТ «НПО ЦКТИ», -1998. - 495 с.

20. Мамаев В. А., Одишарин Г. Э., Семенов Н. И., Точигин А. А. Гидродинамика газожидкостных смесей в трубах. - М.: Недра, 1969.- 207 с.

21. Точигин А. А., Елин Н. Н., Арсенов В. Г. Влияние вязкости жидкой фазы на истинное газосодеожание и область существования расслоенного потока двухфазной смеси в слабонаклоненных трубах // ИФЖ. - 1983. - т. 65, № 2.- C. 217-221.

22. Kosky P. G. Thin Liquid Films Under Simultaneous Shear and Gravity Forces.- Int. J. HeatMassTransfer, 1971. - V. 14. - P. 1220-1224.

23. Безлепкин В. В., Сидоров В. Г., Иванова М. В., Кректунов О. П. Верификация и корректировка модели конденсации кода РАТЕГ/СВЕЧА/ГЕФЕСТ для цилиндрических каналов различной ориентации. - С. 1 - 11. 24. Кутателадзе С. С. Теплоотдача при пленочной конденсации пара внутри горизонтальной трубы. В кн.: Вопросы теплоотдачи и гидравлики двухфазных сред. М.: ГЭИ, 1961. - С. 138-156.
25. Dobson M., Chato J. 1998. Condensation in smooth horizontaltubes. J. Heat Transfer 120, 193-213, http://dx.doi.org/10.1115/1.2830043.

26. Singh A., Ohadi M. M. \& Dessiatoun S. V. (1996). Empirical Modeling of Stratified Wavy Flow Condensation Heat Transfer in Smooth Horizontal Tubes. ASHRAE Trans: Symposia, 9, 596-603.

27. Gnielinski V. New equations for heat and mass transfer in turbulent pipe and channel flow [Text] / V. Gnielinski // Int. Chem. Eng. 1976. - Vol. 16. - P. 359-368.

28. Петухов Б. С., Генин Л. Г., Ковалев С. А. Теплообмен в ядерных энергетических установках. - М.: Атомиздат, 1974. -408 с.

29. Филоненко Г. К. Формула для коэффициента гидравлического сопротивления гладких труб/ В Сб. «Проблемы турбулентности». -М.: ОНТИ, 1936. - С. 8-9.

30. Chato J. C. (1962). Laminar Condensation Inside Horizontal and Inclined Tubes. ASHRAEJ, 4, 52-60.

Received 28 May 2018 Approved 03 July 2018 Available in Internet 30 August 2018 